\title{
A pivotal role of BEX1 in liver progenitor cell expansion in mice
}

Yuting Gu ${ }^{1,2+}$, Weiting Wei ${ }^{3+}$, Yiji Cheng ${ }^{3}$, Bing Wan ${ }^{3}$, Xinyuan Ding ${ }^{4}$, Hui Wang ${ }^{3}$, Yanyun Zhang ${ }^{1,3^{*}}$ (D) and Min Jin ${ }^{1,3^{*}}$

\begin{abstract}
Background: The activation and expansion of bipotent liver progenitor cells (LPCS) are indispensable for liver regeneration after severe or chronic liver injury. However, the underlying molecular mechanisms regulating LPCs and LPC-mediated liver regeneration remain elusive.

Methods: Hepatic brain-expressed X-linked 1 (BEX1) expression was evaluated using microarray screening, real-time polymerase chain reaction, immunoblotting and immunofluorescence. LPC activation and liver injury were studied following a choline-deficient, ethionine-supplemented (CDE) diet in wild-type (WT) and Bex $1^{-1-}$ mice. Proliferation,

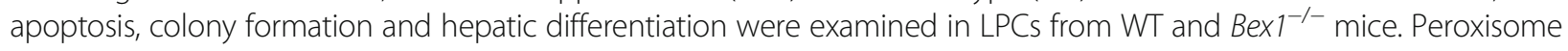
proliferator-activated receptor gamma was detected in Bex1-deficient LPCs and mouse livers, and was silenced to analyse the expansion of LPCs from WT and Bex $1^{-1-}$ mice.

Results: Hepatic BEX1 expression was increased during CDE diet-induced liver injury and was highly elevated primarily in LPCS. Bex $1^{-1-}$ mice fed a CDE diet displayed impaired LPC expansion and liver regeneration. Bex 1 deficiency inhibited LPC proliferation and enhanced LPC apoptosis in vitro. Additionally, Bex1 deficiency inhibited the colony formation of LPCS but had no effect on their hepatic differentiation. Mechanistically, BEX1 inhibited peroxisome proliferator-activated receptor gamma to promote LPC expansion.

Conclusion: Our findings indicate that BEX1 plays a pivotal role in LPC activation and expansion during liver regeneration, potentially providing novel targets for liver regeneration and chronic liver disease therapies.
\end{abstract}

Keywords: Liver progenitor cells, Brain expressed X-linked 1, Expansion, Peroxisome proliferator-activated receptor gamma

\section{Background}

The liver is the largest internal organ in the human body and is vital for the metabolism of nutrients, glycogen storage, drug detoxification, bile secretion, the synthesis of various plasma proteins and immune regulation $[1,2]$. Due to its large volume, complicated functions and anatomical structure, the liver is rather susceptible to damage, pathogen infection and other disorders, such as hepatitis, fibrosis, cirrhosis and even tumours. In response to injury, the liver restores its parenchymal mass through mature liver parenchymal cells, hepatocytes and cholangiocytes. However, parenchymal cell-mediated regeneration is impaired following

\footnotetext{
* Correspondence: yyzhang@sibs.ac.cn; mjin@sibs.ac.cn

${ }^{\dagger}$ Yuting Gu and Weiting Wei contributed equally to this work.

${ }^{1}$ Pediatric Institute of Soochow University, Institutes for Translational

Medicine, Soochow University, Suzhou, Jiangsu, China

Full list of author information is available at the end of the article
}

prolonged or severe liver injury, and ductular reactions (formation of ductular structures) developing in the liver and liver progenitor cells (LPCs) are assumed to be responsible for repairing liver damage [3-5].

LPCs, also known as 'oval cells', are a stem cell population within the liver that displays an ovoid nucleus and scant cytoplasm [2]. Upon massive liver injury and persistent loss of hepatocytes, LPCs can be activated to proliferate and migrate into the hepatic lobule where they differentiate into hepatocytes and biliary epithelial cells for liver regeneration [6]. A correlation has been shown between the extent of liver disease and the magnitude of the accompanying LPC response [7]. LPC expansion occurs in many human liver diseases and experimental animal models [8-10], and LPCs are considered potential targets for liver cell transplantation and therapeutic liver repopulation

(C) The Author(s). 2018 Open Access This article is distributed under the terms of the Creative Commons Attribution 4.0 International License (http://creativecommons.org/licenses/by/4.0/), which permits unrestricted use, distribution, and 
$[11,12]$. Various cytokines, extracellular matrix components and growth factors, such as Wnt, Notch and fibroblast growth factor (FGF), have been demonstrated to be involved in LPC activation and expansion for liver regeneration through the activation of multiple cellular signalling pathways $[8,10,13-16]$. However, the mechanisms regulating LPC activation and expansion remain to be elucidated. Thus, it is of great importance to better understand the mechanisms governing LPC behaviour to potentially develop novel therapeutic strategies for pathological liver injury.

Brain-expressed X-linked 1 (BEX1), an adaptor or modulator of intracellular signalling, was first characterized with reduced expression in F9 teratocarcinoma cells following retinoic acid treatment [17]. BEX1 is involved in P75 neurotrophin receptor signalling, regulating the cell cycle and differentiation of neural stem cells $[18,19]$. BEX1 expression was subsequently reported to be upregulated in spinal cord motor neurons and was required for neurons to recover from injury [20]. BEX1 is also associated with skeletal muscle regeneration after injury [21], suggesting potential effects of BEX1 on tissue regeneration. Additionally, a role for Bex1 as a marker for hepatocyte differentiation/dedifferentiation processes and tumour formation was identified [22]. However, no studies have examined the role of BEX1 in LPC-mediated liver regeneration.

Here, we identified that hepatic BEX1 expression was increased during choline-deficient, ethionine-supplemented (CDE) diet-induced liver injury and was elevated to a high level primarily in LPCs. Interestingly, Bexl deficiency severely impaired LPC expansion and liver regeneration in CDE-induced liver injury by inhibiting the proliferation of and enhancing the apoptosis of LPCs, indicating a critical role for BEX1 in LPC activation. Additionally, BEX1 was required for the colony formation of LPCs but not for their hepatic differentiation. Furthermore, BEX1 inhibited peroxisome proliferator-activated receptor gamma (PPARG), which contributed to the promoting effects of BEX1 on LPC expansion. Our findings identify BEX1 as a critical regulator of LPC activation and expansion during liver injury and indicate that BEX1 may serve as a novel target for liver regeneration and chronic liver disease therapies.

\section{Methods}

\section{Mice and animal models}

C57BL/6 mice were purchased from the Shanghai Laboratory Animal Center of the Chinese Academy of Sciences. 129Sv/Ev wild-type (WT) mice were obtained from the Shanghai Xipuer-Bikai Laboratory Animal Limited Company. Bex1-deficient $\left(B e x 1^{-/-}\right)$mice were kindly provided by Professor Frank L. Margolis, University of Maryland, Baltimore, MD, USA [21]. Female mice 6-8 weeks old were administered a CDE diet (TROPHIC, Nantong, China) supplemented with $0.15 \%$ (w/v)
D,L-ethionine (Sigma-Aldrich, St. Louis, MO, USA) in the drinking water for 3 weeks [23], while control mice received normal chow and drinking water. Rosiglitazone (TCI, Tokyo, Japan) or GW9662 (dose of $2 \mathrm{mg} / \mathrm{kg}$; Selleckchem, Houston, TX, USA) was administered to mice via intraperitoneal injection every second day, for a dose of $50 \mathrm{mg} / \mathrm{kg}$, and dimethyl sulphoxide (DMSO; Sigma-Aldrich) was injected into control mice. All mice were maintained under specific pathogen-free conditions in the vivarium of Shanghai Jiao Tong University School of Medicine. All animal procedures were approved by the Animal Welfare \& Ethics Committee of Shanghai Jiao Tong University School of Medicine.

\section{Microarray}

Total RNA was extracted from samples using TRIzol reagent (Invitrogen, Carlsbad, CA, USA). RNA integrity was checked using the Agilent Bioanalyzer 2100 system (Agilent Technologies, Santa Clara, CA, USA). Total RNA was purified using the RNeasy kit and RNase-Free DNase Set (QIAGEN, Hilden, Germany). RNA labelling and microarray hybridization were performed according to the Affymetrix expression analysis technical manual (Biotechnology Corporation, Shanghai, China). The arrays were scanned using the GeneChip scanner 3000 system (Affymetrix, Santa Clara, CA, USA) and Command Console software 3.1 (Affymetrix) using default settings. Raw data were normalized using the MAS 5.0 algorithm of Gene Spring software 11.0 (Agilent Technologies).

\section{Quantitative real-time polymerase chain reaction (PCR)}

Total RNA was extracted from tissues or cells and was reverse transcribed using a reverse transcription system (TaKaRa, Shiga, Japan). Quantitative real-time polymerase chain reaction was performed using the SYBR Green PCR mix (Roche, Basel, Switzerland) in the ViiA ${ }^{\mathrm{TM}} 7$ Real-Time PCR System (Applied Biosystems, Waltham, MA, USA). $A c t b$ was used as an internal control to normalize for differences in the amount of total RNA in each sample. The primer sequences are listed as follows: Bex1, forward 5' ${ }^{\prime}$-ATGGAGTCCAAAGATCAAGGCG-3' and reverse 5'-CTGGCTCCCTTCTGATGGTA-3'; Epcam, forward 5'-GATCATCGCTGTCATTGT

GG-3' and reverse 5'-CACGGCTAGGCATTAAGCT C-3'; Afp, forward 5'-CCCTCATCCTCCTGCTACA TT-3' and reverse $5^{\prime}$-CGGAACAAACTGGGTAAAG GT-3'; Prom1, forward 5'-GGAAAAGTTGCTCTGCG AAC-3' and reverse 5' -TCTCAAGCTGAAAAGCAGC A-3'; Myc, forward 5'-ACTCGCCTCACTCAGCTCC C-3' and reverse $5^{\prime}$-ACCGTCCGCTCACTCCCTC T-3'; Cdknla, forward 5'-CCTGGTTCCTTGCC ACTTCTT-3' and reverse 5'-CTGTTCTAGGCTGT GACTGCTTC-3'; $B c l$-2, forward 5'-ATGTGTGTG 
GAGAGCGTCAACC-3' and reverse 5' -TGAGCAGAG TCTTCAGAGACAGCC-3'; Alb, forward 5' -TGGGTA ACCTTTCTCCTCCTCC-3' and reverse $5^{\prime}$-CACTCTT GTGTGCTTCTCGGC-3'; G6pc, forward 5' -CATCAA TCTCCTCTGGGTGGC-3' and reverse $5^{\prime}$-CGTT GCTGTAGTAGTCGGTGTCC-3'; Krt19, forward 5' -A CCCTCCCGAGATTACAACCAC-3' and reverse 5' $-\mathrm{C}$ AAGGCGTGTTCTGTCTCAAAC-3'; Krt7, forward 5'-AGGAGATCAACCGACGCAC-3' and reverse 5'-G TCTCGTGAAGGGTCTTGAGG-3'; and Pparg, forward 5'-CCACAGTTGATTTCTCCAGCATTTC-3' and reverse 5 '-CAGGTTCTACTTTGATCGCACTTTG-3'. All primers were synthesized by Sangon Biotech (Shanghai, China).

\section{Immunoblotting}

Tissues or cells were harvested and lysed with ice-cold RIPA buffer (Beyotime, Haimen, China) containing protease and phosphatase inhibitors (Roche). Lysates were clarified by centrifugation at $15,000 \times g$ for $30 \mathrm{~min}$. The protein concentration of the supernatant fraction was determined by the Bradford assay (Thermo Fisher Scientific, Waltham, MA, USA). Protein samples were diluted in $4 \times$ SDS loading buffer (TaKaRa), heated to $95{ }^{\circ} \mathrm{C}$ for $5 \mathrm{~min}$ and separated in a 10\% SDS-polyacrylamide gel. The proteins were electroblotted onto polyvinylidene fluoride membranes and incubated for $1 \mathrm{~h}$ in $5 \%$ bovine serum albumin in phosphate-buffered saline (PBS) or non-fat dry milk dissolved in PBS containing $0.1 \%$ Tween-20 (PBST) at room temperature. The blotting membranes were incubated with primary antibodies to BEX1 (kindly provided by Professor Frank L. Margolis), CDKN1a, B-cell lymphoma-2 (Bcl-2), poly ADP-ribose polymerase (PARP), cleaved PARP and PPARG (Cell Signaling Technology, Danvers, MA, USA) overnight at $4^{\circ}$ $\mathrm{C}$, extensively washed in PBST, incubated with HRP-conjugated secondary antibody (Cell Signaling Technology) for $1 \mathrm{~h}$ at room temperature and washed again with PBST. The blotting membranes were developed with chemiluminescent reagents (Millipore, Billerica, MA, USA) according to the manufacturer's instructions. The densitometry of the bands was quantified using ImageJ software.

\section{Immunofluorescence (IF)}

Liver tissues were dissected from mice and were fixed for $4 \mathrm{~h}$ in $4 \%$ paraformaldehyde (PFA), followed by incubation overnight in $30 \%$ sucrose before embedding in OCT. Frozen blocks were cut into $5-\mu \mathrm{m}$ sections and stained as described previously $[24,25]$. The primary antibodies included anti-BEX1 (kindly provided by Professor Frank L. Margolis), anti-epithelial cell adhesion molecule (EpCAM) and anti-Ki67 (Abcam, Cambridge, MA, USA). The secondary antibody was Alexa 488-conjugated and Alexa 555-conjugated antibodies (Invitrogen). The slides were mounted and examined by confocal microscopy (ZEISS, Oberkochen, Germany).

\section{Histological analysis}

Liver tissues were dissected from mice and were immediately fixed in $4 \%$ PFA and embedded in paraffin. Paraffin-embedded $5-\mu \mathrm{m}$ sections of the liver were stained with haematoxylin and eosin (H\&E), and frozen $5-\mu \mathrm{m}$ sections of the liver were stained with Oil Red O, and the sections were then examined by light microscopy.

\section{LPC isolation and culture}

LPCs were isolated as described previously [24]. Briefly, liver tissues were removed from CDE diet-fed mice after in-situ perfusion using a two-step collagenase perfusion method and then were incubated with $1 \mathrm{mg} / \mathrm{ml}$ collagenase $\mathrm{D}$ (Roche) and $1 \mathrm{mg} / \mathrm{ml}$ pronase (Roche) at $37^{\circ} \mathrm{C}$ for $30 \mathrm{~min}$. Non-parenchymal cells (NPCs) were separated from hepatocytes by repeated low-speed centrifugation. Next, NPCs were collected and suspended in a discontinuous gradient of $20 \%$ and 50\% Percoll (GE Healthcare, Pittsburgh, PA, USA) and centrifuged continuously at $1400 \times g$ for $20 \mathrm{~min}$ to enrich LPCs. The enriched LPCs were labelled with APC-conjugated anti-EpCAM and FITC-conjugated anti-CD45 (eBioscience, San Diego, CA, USA) antibodies, and $\mathrm{EpCAM}^{+} \mathrm{CD} 45^{-}$cells were isolated by fluorescence-activated cell sorting. These LPCs were cultured in type I collagen-coated dishes (BD Biosciences, San Jose, CA, USA). The standard culture medium for LPCs was DMEM/F12 (Gibco, Grand Island, NY, USA) supplemented with $10 \%$ foetal bovine serum, $1 \mu \mathrm{g} / \mathrm{ml}$ insulin (Sigma-Aldrich), $1 \times 10^{-7} \mathrm{~mol} / \mathrm{L}$ dexamethasone (Sigma-Aldrich), 1\% penicillin/streptomycin (Invitrogen), $50 \mathrm{ng} / \mathrm{ml}$ hepatocyte growth factor (PeproTech, Rocky Hill, NJ, USA), $20 \mathrm{ng} / \mathrm{ml}$ epidermal growth factor (PeproTech), $20 \mathrm{ng} / \mathrm{ml} \mathrm{FGF} \mathrm{(PeproTech)} \mathrm{and} 1 \times$ InsulinTransferrin-Selenium-Ethanolamine (Invitrogen).

\section{Flow cytometry}

Cells were washed with PBS, and the pellets were resuspended in PBS with $2.5 \%$ foetal bovine serum at a concentration of $5 \times 10^{5}$ cells per $50 \mu$ l. Cells were stained with a combination of APC-conjugated-EpCAM, APC-conjugated-CD49f, PE-conjugated-CD44 and FITC-conjugated-CD45 antibody (eBioscience) for $30 \mathrm{~min}$ at $4{ }^{\circ} \mathrm{C}$ and then analysed by flow cytometry using a BD FACSCalibur Flow Cytometry System (BD Biosciences). For apoptosis analysis, the cells were stained with annexin $\mathrm{V}$ and propidium iodide (PI; eBioscience) for $10 \mathrm{~min}$ and analysed by flow cytometry. For the bromodeoxyuridine (BrdU; BD Biosciences) assay, the cells were incubated with $\mathrm{BrdU}$ at a final 
concentration of $10 \mu \mathrm{M}$ in the cell culture medium for $4 \mathrm{~h}$. The cells were harvested and washed with PBS. After fixation and permeabilization, the cells were treated with $300 \mu \mathrm{g} / \mathrm{ml}$ DNase (Roche). The incorporated BrdU was stained with anti-BrdU-FITC antibody (BD Biosciences) and then analysed by flow cytometry.

\section{Cell Counting Kit-8 (CCK8) assay}

Cell proliferation and viability were monitored using CCK8 (Dojindo, Kumamoto, Japan) according to the manufacturer's instructions. The cells were seeded onto 96-well plates, and cell proliferation and viability were assessed at the indicated time points by measurement of the absorbance at $450 \mathrm{~nm}$.

\section{Lentiviral vector construction}

Oligonucleotides with the following nucleotide sequences were used to clone shRNA-encoding sequences into a lentiviral vector PLKO.1 puro, a gift from Bob Weinberg (Addgene, Cambridge, MA, USA): mouse BEX1 (shBex1), 5'-CCGGTTATGTAGATCTCTCCCTGTTCTCGAGAA CAGGGAGAGATCTACATAATTTTTG-3'; and scrambled control (shNC), 5'-CCGGCCTAAGGTTAAGTCG CCCTCGCTCGAGCGAGGGCGACTTAACCTTAGGT TTTTG-3' (synthesized by Sangon Biotech). High-titre lentiviral stocks were produced, and liver epithelial progenitor cells (LEPCs), an LPC cell line [26], were infected with scrambled control lentivirus (shNC) or lentivirus expressing shRNA inhibiting BEX1 (shBex1). Cells resistant to puromycin $(2 \mu \mathrm{g} / \mathrm{ml})$ were selected and passaged for further study. Production of high-titre lentiviral stocks and lentiviral stocks transfection were handled according to the manufacturer's protocol.

\section{Clonogenic colony-forming assay}

The cells were diluted and seeded at 200 cells per well of a six-well plate. After incubation for 10 days, the cells were washed with PBS, fixed with 4\% PFA and stained with crystal violet. The numbers of visible colonies were counted.

\section{Hepatic differentiation induction}

Hepatic differentiation was induced as described previously [27]. Briefly, LPCs were grown to confluence, washed with PBS and cultured in medium supplemented with 20\% Matrigel (BD Biosciences), $40 \mathrm{ng} / \mathrm{ml}$ oncostatin M (R\&D Systems, Minneapolis, MN, USA), $25 \mathrm{ng} / \mathrm{ml}$ hepatocyte growth factor, $25 \mathrm{ng} / \mathrm{ml}$ epidermal growth factor, and $10^{-7} \mathrm{M}$ dexamethasone for 7 days. Next, the cells were harvested for real-time PCR or subjected to periodic acid-Schiff (PAS) staining. Cells grown on chamber slides were fixed with 4\% PFA for $30 \mathrm{~min}$ and washed with PBS. The slides were then incubated in periodic acid solution for $5 \mathrm{~min}$ and rinsed with several changes of distilled water. Finally, the slides were incubated in Schiff's reagent (Sigma-Aldrich) for $15 \mathrm{~min}$, washed in running tap water for $5 \mathrm{~min}$, dehydrated and mounted with xylene-based mounting medium.

\section{Statistical analyses}

Statistical analyses were performed using SPSS. All values are expressed as the mean \pm SEM. Statistical significance was evaluated using an unpaired non-parametric test. $P<0.05$ was considered significant.

\section{Results}

\section{Hepatic BEX1 expression is upregulated in response to a CDE diet}

To investigate the molecular mechanisms regulating LPC activation and LPC-mediated liver regeneration, we fed mice a modified CDE diet to induce liver damage [23] and performed microarray analysis on the liver tissues of mice fed with chow and CDE diets. Based on the changes in the gene expression profiles, we found that Bex 1, a previously unknown gene involved in liver regeneration, was greatly upregulated in the liver tissues of CDE diet-fed mice compared with those of chow diet-fed mice (Fig. 1a). We then assessed the mRNA level of Bex 1 in the liver tissues of mice fed with the chow and CDE diets by real-time PCR and found that hepatic Bex1 mRNA was significantly higher in the CDE diet-fed mice (Fig. 1b). Immunoblotting analysis revealed a similar result for the protein level of hepatic BEX1 (Fig. 1c). We next examined whether BEX1 was expressed in LPCs. LPCs were induced around the portal vein by the CDE diet, which were identified by the expression of a specific marker, EpCAM [28]. We found that BEX1 was rarely expressed in the liver tissues of chow-fed mice, but was strongly expressed in $\mathrm{EpCAM}^{+}$ LPCs and some surrounding hepatocytes in CDE diet-fed mice (Fig. 1d, e). Altogether, our data showed that hepatic BEX1 expression was increased during CDE diet-induced liver injury and was elevated to a high level primarily in LPCs, implicating the essential role of BEX1 for LPC activation and LPC-mediated liver regeneration.

\section{BEX1 is critical for LPC expansion and liver regeneration in response to a CDE diet}

To determine whether BEX1 functionally regulates LPC activation and LPC-mediated liver regeneration, we fed the chow or CDE diet to WT and $B e x 1^{-1-}$ mice [21]. Bex1 deficiency in Bex $1^{-/-}$mice was confirmed by PCR with genomic DNA (Additional file 1: Figure S1), and Bex 1 mRNA expression was dramatically downregulated in the liver tissues of $B e x 1^{-/-}$mice compared with those of WT mice fed with either the chow or CDE diet (Fig. 2a). Histological analysis showed that the livers of both chow diet-fed WT and $B e x 1^{-/-}$mice were 


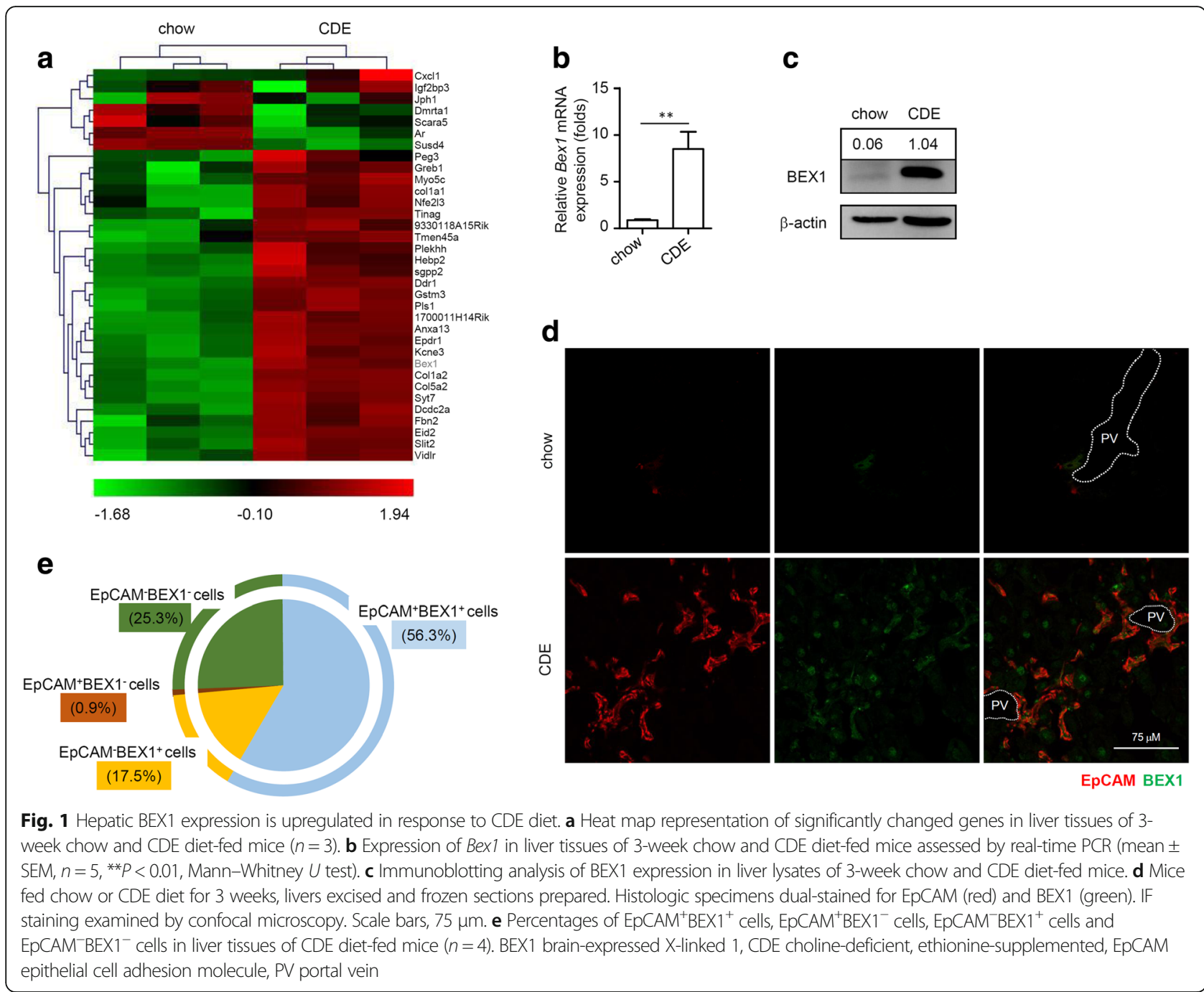

structurally integrated. Following the CDE diet, ductular reactions were induced in WT mice as reported previ-

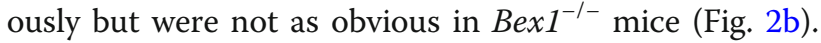
Furthermore, compared with CDE diet-fed WT mice, the livers of CDE diet-fed $B e x 1^{-1-}$ mice exhibited more serious macrovesicular steatosis, indicated by more macrovesicular fat droplets and fat accumulation (Fig. $2 \mathrm{~b}, \mathrm{c})$. These CDE diet-fed $B e x 1^{-/-}$mice also showed a dramatic increase in serum alanine aminotransferase (ALT) levels compared with the CDE diet-fed WT mice (Fig. 2d), indicating substantially more severe liver injury. These results suggest that $B e x 1^{-1-}$ mice have impaired liver regeneration capacity in response to the CDE diet.

To test LPC activation in BEX1-regulated liver regeneration, we first measured the expression levels of the LPC markers EpCAM, $\alpha$-fetoprotein (AFP) and prominin-1 (PROM1) in the liver tissues of WT and $B e x 1^{-1-}$ mice fed with the chow or CDE diet. The
mRNA levels of Epcam, Afp and Prom1 were increased in the liver tissues of WT mice after the CDE diet (Fig. 2e). Notably, the liver tissues of the CDE diet-fed $\mathrm{Bex}^{-1-}$ mice showed markedly lower mRNA levels of Epcam, Afp and Prom1 than those of CDE diet-fed WT mice (Fig. 2e). IF staining demonstrated

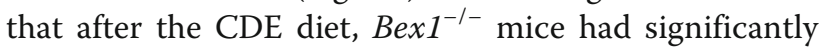
lower numbers of $\mathrm{EpCAM}^{+}$and $\mathrm{Ki}^{+} 7^{+} \mathrm{EpCAM}^{+} \mathrm{LPCs}$ than WT mice (Fig. 2f, g). Next, we tested the mRNA levels of the cell cycle regulators $M y c$ and Cdkn1a, which regulate cellular proliferation, in liver tissues. As expected, the $M y c$ transcript level was upregulated in CDE diet-fed WT mice but not in CDE diet-fed $B e x 1^{-1-}$ mice, while the cell cycle-dependent kinase inhibitor Cdkn1a level was upregulated in CDE diet-fed $B e x 1^{-/-}$mice (Fig. 2h). CDKN1A induction was also assessed by immunoblotting analysis, which showed similar results (Fig. 2i). Taken together, these results indicate that BEX1 is required for LPC 


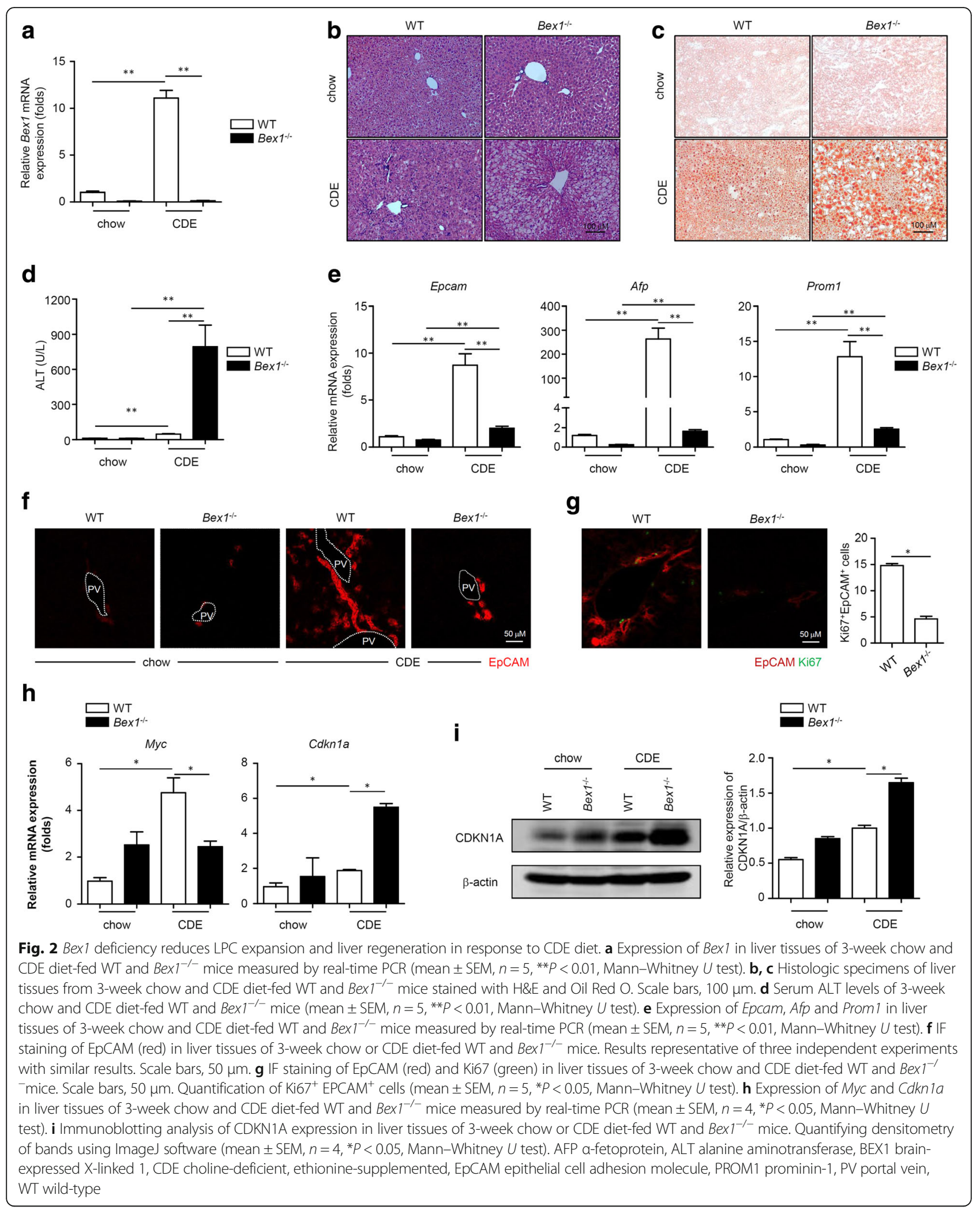


expansion and proliferation in the CDE diet-induced liver injury model.

\section{BEX1 promotes LPC proliferation and prevents LPC apoptosis in vitro}

To further clarify the effect of BEX1 on LPC proliferation, we isolated $\mathrm{EpCAM}^{+} \mathrm{CD} 45^{-} \mathrm{LPCs}$ from WT and $B e x 1^{-1-}$ mice fed with the CDE diet. Bex1 mRNA expression was significantly lower in LPCs from $B e x 1^{-1-}$ mice than in those from WT mice (Fig. 3a). LPCs from WT and $B e x 1^{-1-}$ mice displayed a similar phenotype, $\mathrm{EpCAM}^{+} \mathrm{CD} 49 \mathrm{f}^{+} \mathrm{CD} 44^{+} \mathrm{CD} 45^{-}$(Fig. 3b). However, in vitro proliferation assays showed that the proliferation of LPCs from WT mice was higher than those from $B e x 1^{-1}$ - mice (Fig. 3c). The decreased $M y c$ expression and increased $C d k n 1 a$ mRNA expression were consistent with

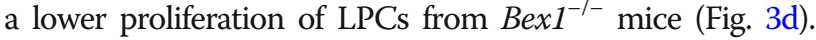
Meanwhile, Bex 1 was knocked down in LEPCs using a lentivirus expressing shRNA specific to BEX1 (shBex1). LEPCs infected with a lentivirus expressing scrambled shRNA (shNC) were used as controls (Fig. 3e). The proliferation ability of shBex1-LEPCs was also impaired (Fig. 3f, g). By contrast, the proliferation of BEX1-overexpressed LEPCs was enhanced, as shown by CCK 8 and BrdU analysis (Fig. $3 \mathrm{~h}-\mathrm{j}$ ).

Reduced apoptosis alone, or combined with promoted proliferation, contributed to cellular expansion. We next tested whether the inhibition of BEX1 would affect LPC viability. LPCs from WT and Bex $1^{-/-}$mice were treated with etoposide, a cell apoptosis inducer [29], and cell viability was detected by CCK8 and annexin V/PI staining. As expected, both cell types displayed obvious cell

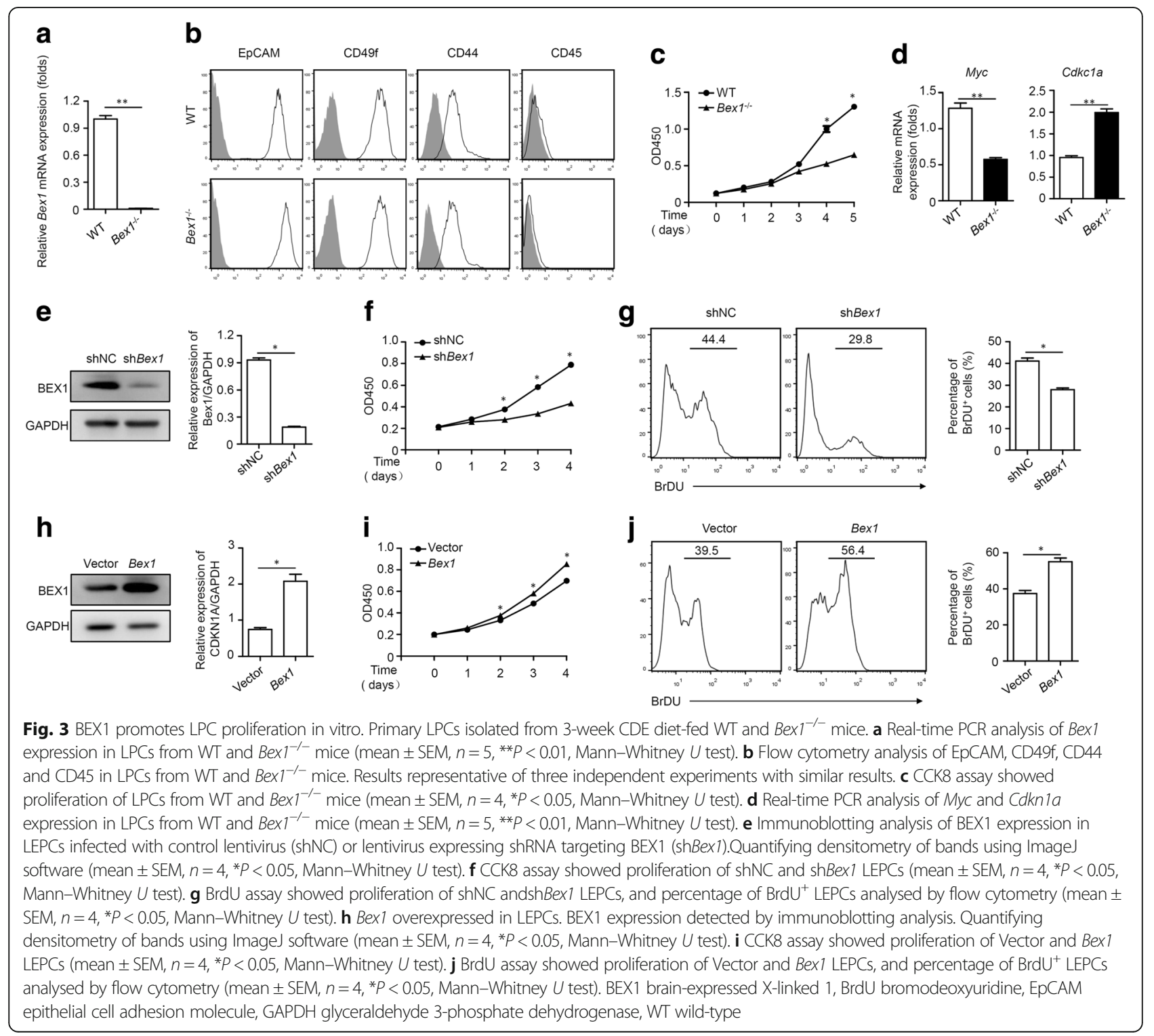


apoptosis with etoposide treatment; however, the level of apoptosis in LPCs from Bex1 $1^{-1-}$ mice was higher than that in LPCs from WT mice (Fig. 4a, b). The anti-apoptotic protein $\mathrm{Bcl}-2$ was inhibited and the cleaved PARP was induced after etoposide treatment in LPCs from WT mice, and these effects were enhanced in LPCs from $B e x 1^{-1-}$ mice, also indicating enhanced apoptosis (Fig. 4c, d). In contrast, etoposide-induced cell apoptosis was alleviated in BEX1-overexpressed LEPCs (Fig. 4e). Taken together, our findings illustrate that BEX1 promotes proliferation and suppresses apoptosis of LPCs to augment cellular expansion and liver regeneration.

\section{BEX1 is not required for hepatic differentiation of LPCs}

Self-renewal and differentiation are two characteristics of stem/progenitor cells, including LPCs, and these abilities of LPCs play critical roles in their activation and expansion during liver regeneration [3]. The efficiency of LPC self-renewal was assessed by the rate of colony formation in the clonogenic colony-forming assay. The

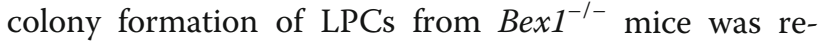
duced compared with those from WT mice (Fig. 5a). Similar results were also detected in shNC and $\operatorname{sh} B e x 1$
LEPCs (Fig. 5b). Furthermore, we performed PAS staining for glycogen deposition to detect the hepatic differentiation of LPCs. LPCs from both WT and Bex1 $1^{-/-}$ mice could differentiate into hepatocytes upon induction with rare differences (Fig. 5c). We also analysed the hepatocyte markers glucose 6-phosphatase (G-6-Pase) and albumin (ALB) and the cholangiocyte markers cytokeratin-19 (CK-19) and CK-7. Real-time PCR analysis demonstrated that hepatic differentiation-induced upregulation of G6pc and Alb mRNA expression, as well as downregulation of $\mathrm{Krt19}$ and $\mathrm{Krt7}$ mRNA expression, showed no changes (Fig. 5d). These results indicate that BEX1 is required for the colony formation of LPCs but not for their hepatic differentiation.

\section{BEX1 inhibits PPARG to regulate LPC expansion}

PPARG, a nuclear receptor, plays important roles in LPC cell growth and ability during liver injury [30-32]. Thus, the roles of PPARG in BEX1-regulated LPC expansion were explored. PPAPG expression in LPCs from Bex1 $1^{-/-}$ mice was higher than that in LPCs from WT mice, as detected by real-time PCR and immunoblotting analysis (Fig. 6a, b). By contrast, the protein level of PPAPG was decreased in BEX1-overexpressed LEPCs (Fig. 6c). The
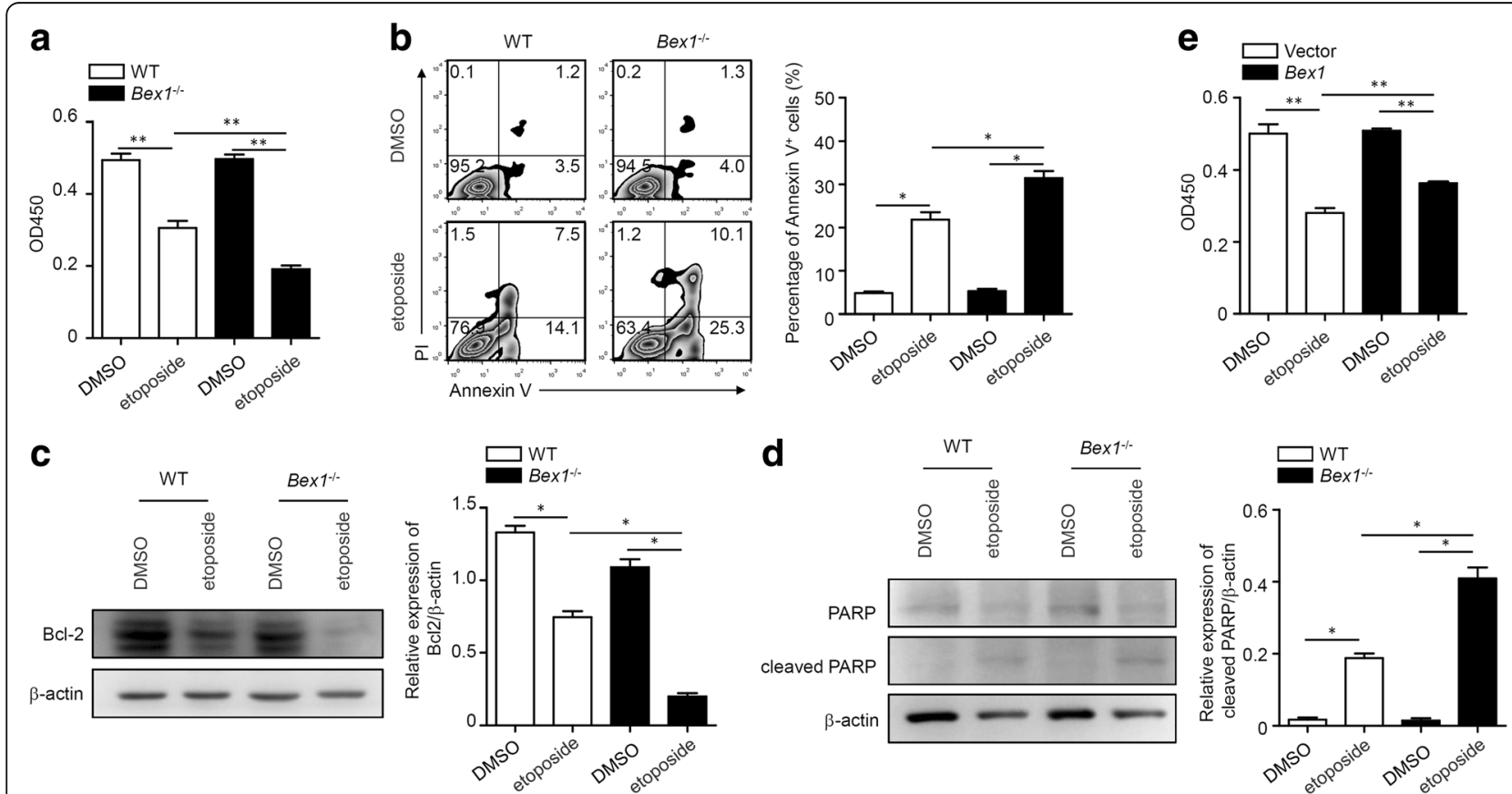

Fig. 4 BEX1 prevents LPC apoptosis in vitro. Primary LPCs isolated from 3-week CDE diet-fed WT and Bex $1^{-/-}$mice as described in Methods. a LPCS from WT and Bex $1^{-1-}$ mice treated with DMSO or $40 \mu \mathrm{M}$ etoposide for $24 \mathrm{~h}$, and cell viability quantified by CCK8 assay (mean \pm SEM, $n=5$, ${ }^{* *} P<0.01$, Mann-Whitney $U$ test). $\mathbf{b}$ Cell apoptosis of LPCs from WT and Bex $1^{-1-}$ mice treated with DMSO or $40 \mu \mathrm{M}$ etoposide for $24 \mathrm{~h}$ detected by annexin V/PI staining (mean \pm SEM $, n=4,{ }^{*} P<0.05$, Mann-Whitney $U$ test). c, $\mathbf{d}$ LPCS from WT and Bex ${ }^{-/-}$mice treated with DMSO or $40 \mu M$ etoposide for $24 \mathrm{~h}$, and expression of Bcl-2, PARP and cleaved PARP detected by immunoblotting analysis. Quantifying densitometry of bands using ImageJ software (mean $\pm S E M, n=4,{ }^{*} P<0.05$, Mann-Whitney $U$ test). e Vector and Bex 1 LEPCS treated with DMSO or $40 \mu M$ etoposide for $24 \mathrm{~h}$, and cell viability quantified by CCK8 assay (mean $\pm \mathrm{SEM}, n=5$, ${ }^{* *} P<0.01$, Mann-Whitney $U$ test). BCl-2 B-cell lymphoma-2, BEX 1 brainexpressed X-linked 1, DMSO dimethyl sulphoxide, PARP poly ADP-ribose polymerase, PI propidium iodide, WT wild-type 


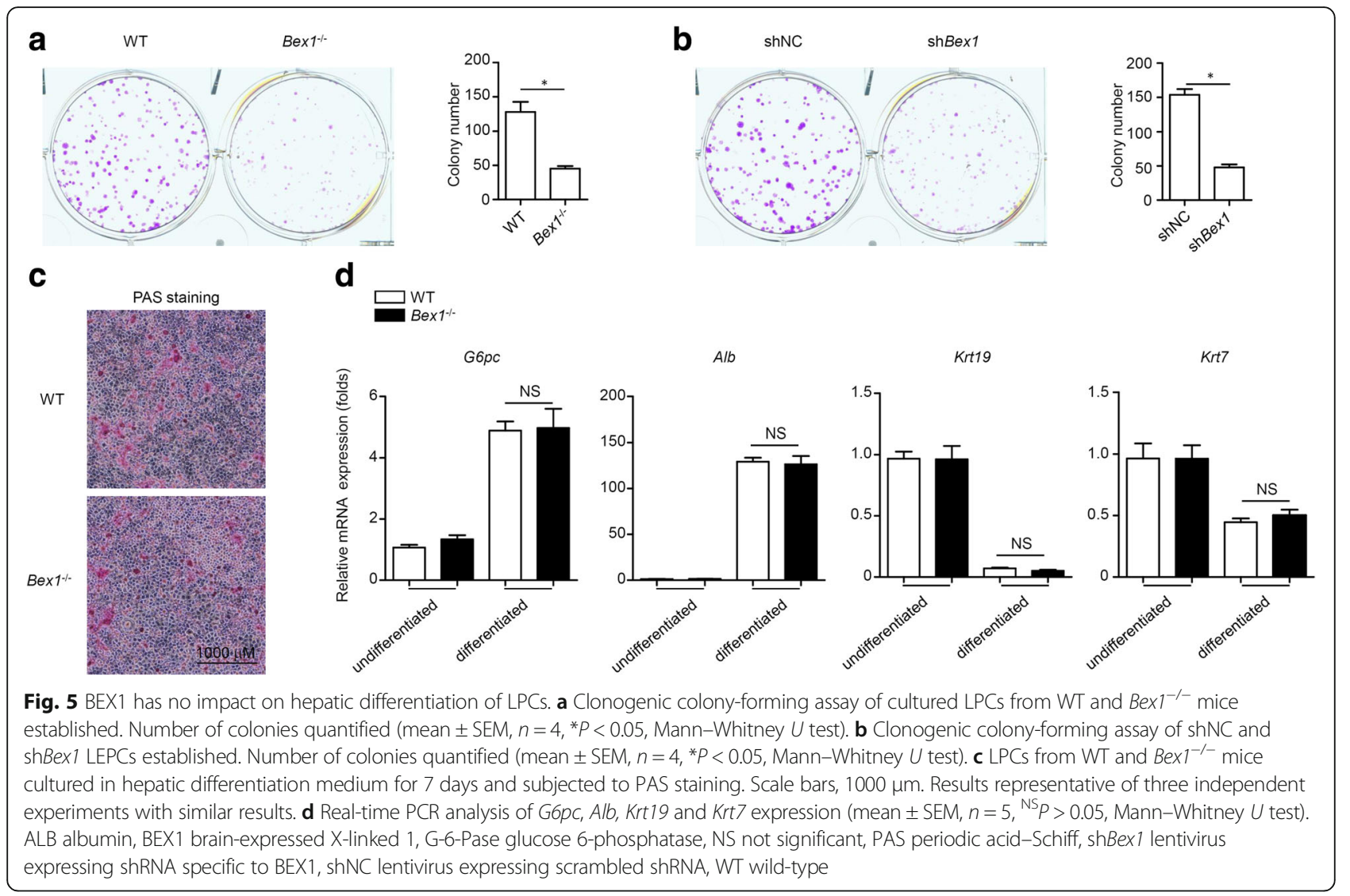

mRNA and protein levels of PPARG were also significantly increased in the liver tissues of CDE diet-fed $B e x 1^{-1-}$ mice compared with those in the liver tissues of CDE diet-fed WT mice (Fig. 6d, e). We next administered rosiglitazone, a PPARG-specific agonist, to CDE diet-fed WT mice to confirm the role of PPARG as a regulator for LPC expansion in liver regeneration. As expected, rosiglitazone increased Pparg expression and decreased Epcam expression in CDE diet-fed WT mice (Fig. 6f). Flow cytometry analysis demonstrated that rosiglitazone treatment reduced the percentage of EpCAM $^{+}$LPCs in the liver tissues of CDE diet-fed WT mice (Fig. 6g).

To further determine whether PPARG is involved in BEX1-mediated LPC expansion, we silenced Pparg in

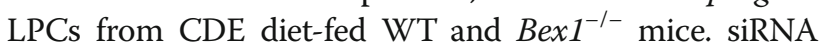
specific to Pparg reduced the mRNA and protein levels of PPARG in LPCs (Fig. 7a, b). Silencing Pparg in LPCs from WT mice enhanced LPC proliferation (Fig. 7c). Moreover, silencing Pparg reversed the inhibited proliferation of LPCs from Bex1 ${ }^{-/-}$mice (Fig. 7c). The increased $M y c$ expression and decreased Cdkn1a expression were consistent with the enhanced proliferation of LPCs from both WT and Bex $1^{-1-}$ mice (Fig. 7d). The apoptosis of LPCs was also analysed. As shown in Fig. 7e, Pparg knockdown increased cell viability in LPCs with etoposide treatment

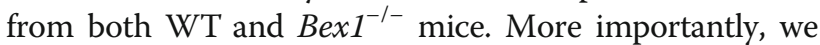
next administered CDE diet-fed WT and $B e x 1^{-/-}$mice with the PPARG antagonist GW9662, to confirm the role of PPARG in BEX1-regulated LPC expansion in liver regeneration. GW9662 increased Epcam expression and the percentage of $\mathrm{EpCAM}^{+}$LPCs in the liver tissues of CDE diet-fed WT mice, and reversed the decreased Epcam expression and the decreased percentage of $\mathrm{EpCAM}^{+} \mathrm{LPCs}$ in the liver tissues of CDE diet-fed $B e x 1^{-/-}$mice (Fig. 7f, g). H\&E analysis and serum ALT detection demonstrated that GW9662 inhibited severe liver injury in CDE diet-fed Bex $1^{-/}$mice (Fig. 7h, i). These results together suggest that BEX1 inhibits PPARG to regulate LPC expansion.

\section{Discussion}

Liver regeneration under chronic or severe liver injury is not well defined. LPCs are activated during severe and persistent liver diseases and can repopulate the liver, thus improving liver function and architecture [33]. However, the mechanisms of LPC regulation under physiological and pathological conditions are not fully understood and need to be explored. In this study, we identified BEX1 as an essential regulator of LPC activation during liver regeneration because Bex 1 deficiency 

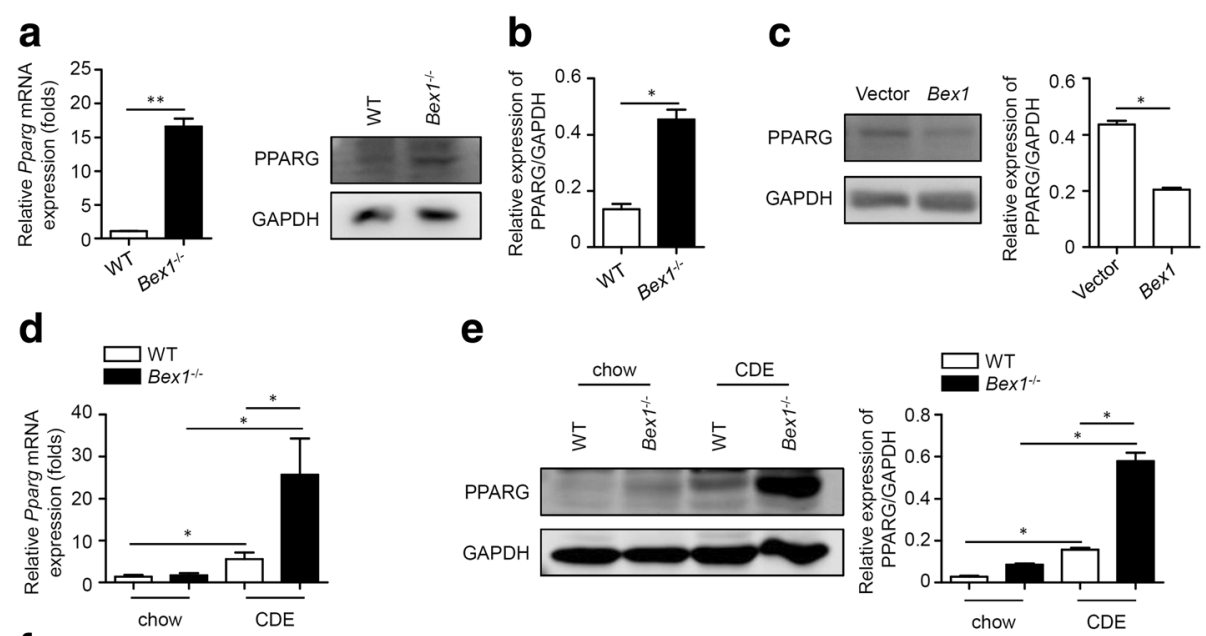

e
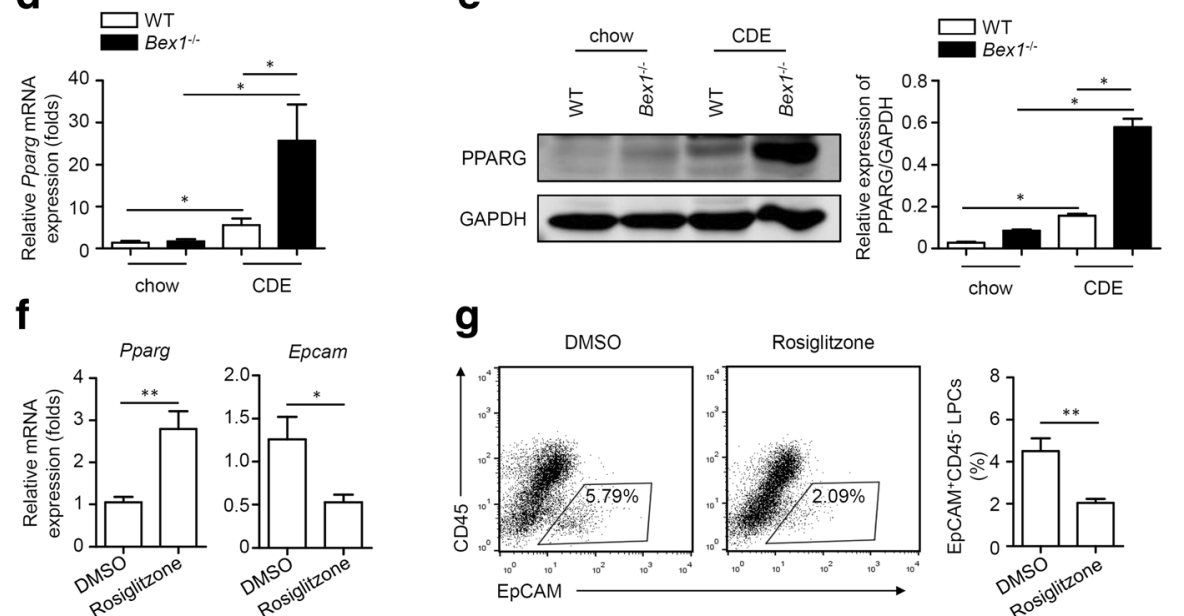

g

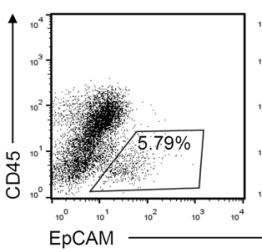

Rosiglitzone

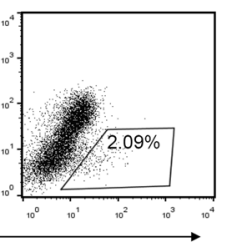

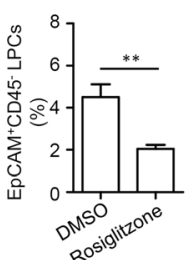

Fig. 6 BEX1 inhibits PPARG in LPCs and liver tissues in response to CDE diet. a Real-time PCR analysis of Pparg mRNA level in LPCs from WT and Bex $1^{-1-}$ mice (mean \pm SEM, $n=6,{ }^{*} P<0.01$, Mann-Whitney $U$ test). $\mathbf{b}$ Immunoblotting analysis of PPARG protein level in LPCs from WT and Bex $1^{-1-}$ mice. Quantifying densitometry of bands using ImageJ software (mean $\pm S E M, n=4,{ }^{*} P<0.05$, Mann-Whitney $U$ test). c Immunoblotting analysis of PPARG protein level in Vector and Bex 1 LEPCs. Quantifying densitometry of bands using ImageJ software (mean \pm SEM, $n=4$, ${ }^{*}<<0.05$, Mann-Whitney $U$ test). d Real-time PCR analysis of Pparg expression in liver tissues of 3-week chow and CDE diet-fed WT and Bex $1^{-/-}$mice (mean \pm SEM, $n=4-5$, ${ }^{*} P<0.05$, Mann-Whitney $U$ test). e Immunoblotting analysis of PPARG protein level in liver tissues of 3-week chow and CDE diet-fed WT and Bex $1^{-1-}$ mice. Quantifying densitometry of bands using ImageJ software (mean $\pm S E M, n=4,{ }^{*} P<0.05, M a n n-W h i t n e y ~ U$ test). $\mathbf{f}$ Real-time PCR analysis of Pparg and Epcam expression in liver tissues of 3-week CDE diet-fed WT mice with DMSO or rosiglitazone treatment (mean $\pm \mathrm{SEM}, n=5,{ }^{*} P<0.05,{ }^{*} P<0.01$, Mann-Whitney $U$ test). g Flow cytometry analysis of percentage of EPCAM ${ }^{+} C D 45^{-} L^{2}$ Cs in NPCs in livers of 3-week-old CDE diet-fed WT mice with DMSO or rosiglitazone treatment (mean \pm SEM, $n=5$, ${ }^{* *} P<0.01, M a n n-W h i t n e y ~ U$ test). BEX1 brain-expressed X-linked 1, CDE choline-deficient, ethionine-supplemented, DMSO dimethyl sulphoxide, EpCAM epithelial cell adhesion molecule, GAPDH glyceraldehyde 3-phosphate dehydrogenase, LPC liver progenitor cell, PPARG peroxisome proliferator-activated receptor gamma, WT wild-type

severely impaired LPC expansion in CDE diet-induced liver injury by inhibiting the proliferation of and enhancing the apoptosis of LPCs. We further demonstrated that BEX1 inhibited PPARG, which contributed to the promoting effects of BEX1 on LPC expansion.

Previous studies have reported that BEX1 is highly expressed in the brain and can be detected in several peripheral tissues [34, 35]. However, in liver tissues, BEX1 is highly expressed after birth but is then subsequently downregulated, with only a marginal mRNA level detectable in adult mouse livers [35]. The Bex1 transcript level has also been shown to be increased during hepatocyte dedifferentiation, and Bex1 is considered a marker for hepatocyte differentiation/dedifferentiation processes and tumour formation [22]. Bex1 expression was significantly increased in hepatocellular carcinoma cell lines compared with normal hepatocyte cell lines, promoting cell proliferation [36]. Here, we performed microarray analysis and unexpectedly identified that hepatic BEX1 expression was increased during CDE diet-induced liver injury. IF staining showed co-localized signals for EpCAM and BEX1, indicating high expression of BEX1 in LPCs. We also observed a population of $\mathrm{BEX}^{+}$hepatocytes in CDE diet-fed mice. We speculated that these cells may be newly formed hepatocytes arising from differentiated progenitors, but this requires further confirmation.

BEX1 has been demonstrated to play critical roles in muscle and neural regeneration [18-21]. Considering the high expression of BEX1 in LPCs, we hypothesized that BEX1 might be involved in regulating LPC activation during liver regeneration. As expected, $B e x 1^{-/-}$mice demonstrated reduced LPC expansion and increased liver injury in response to a CDE diet. Proliferation and apoptosis are tightly coupled, and cell cycle regulators can influence both cell division and cell death, thereby sustaining LPC 


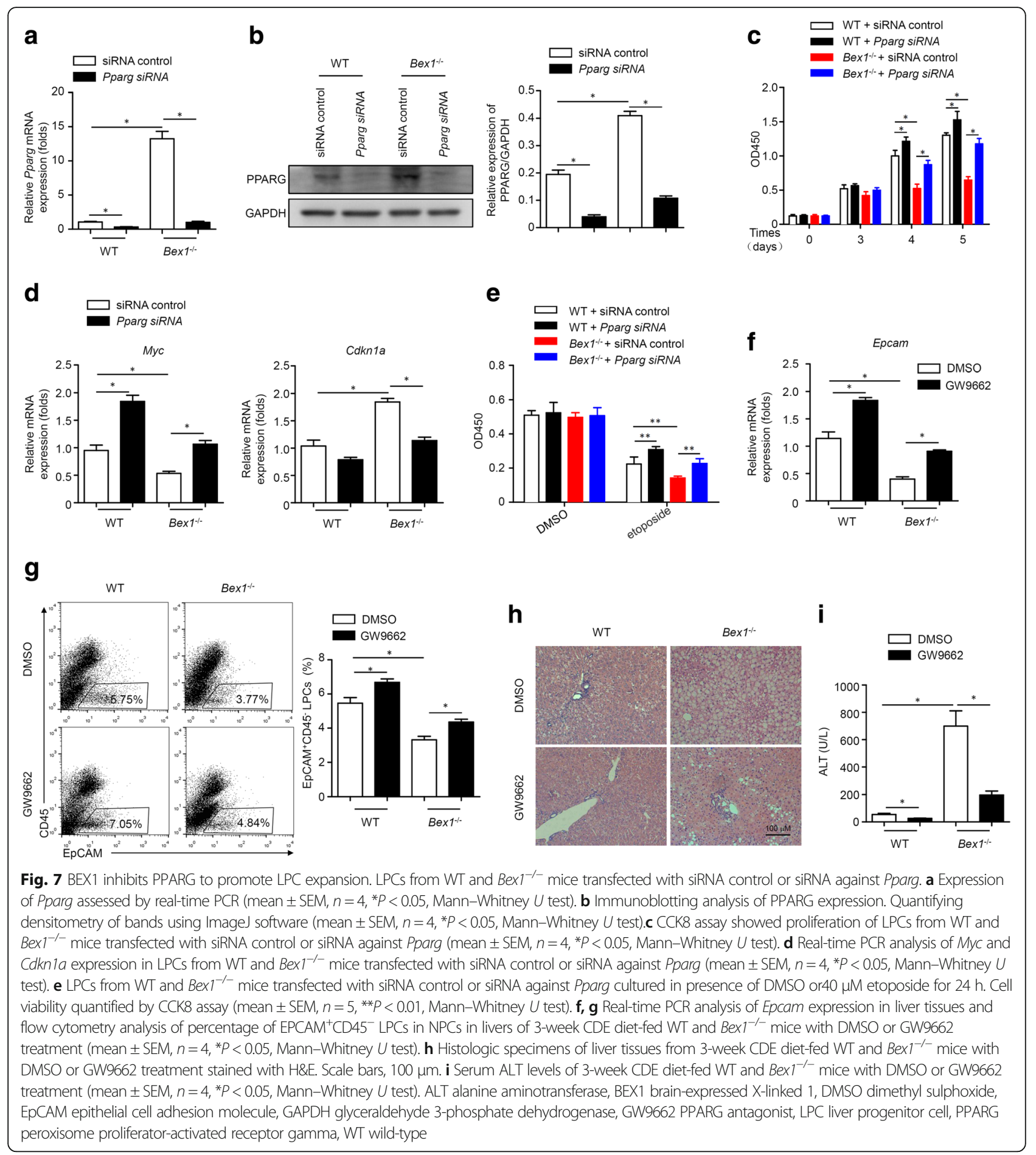

expansion. We found that BEX1 promoted LPC proliferation in vivo and in vitro. Furthermore, the contribution of BEX1 to LPC expansion occurs, at least partially, through the regulation of the cell cycle, based on the upregulation of MYC and the downregulation of CDKN1A. Simultaneously, Bex1 deficiency enhanced etoposide-induced LPC apoptosis, while BEX1 overexpression alleviated apoptosis. Obviously, BEX1 is of great importance in the regulation of LPC expansion through regulating proliferation and apoptosis. BEX1 has been reported to be involved in nerve growth factor-mediated neural stem cell survival through cell cycle regulation [18]. Thus, it is of great interest whether BEX1 acts downstream of Wnt or FGF or other mitogens in LPCs to regulate their expansion. 
Self-renewal and differentiation are two characteristics of LPCs that play critical roles in their activation and expansion during liver regeneration [3]. Our results showed that BEX1 inhibition decreased the colony formation of both LPCs and LEPCs. Regarding differentiation, it was reported that Bex 1 deficiency accelerated the neuronal differentiation of neural stem cells [18]. However, in our study, Bex 1 deficiency had no effect on the hepatic differentiation of LPCs, as characterized by the similar levels of glycogen deposition, hepatocyte markers (G-6-Pase and ALB) and cholangiocyte markers (CK-19 and CK-7). This finding indicates that there may be different regulatory mechanisms of BEX1 in different cell types.

PPARG, a member of the PPAR family belonging to the nuclear receptor superfamily, is crucial for development and functions as a lipid sensor to regulate lipid metabolism [37]. PPARG is expressed at a low level in normal human and mouse livers and plays divergent roles in the pathogenesis of liver injury [32]. Our data showed a significantly higher expression of PPARG in LPCs and liver tissues from CDE diet-fed $B e x 1^{-1-}$ mice than in those from CDE diet-fed WT mice. Additionally, PPARG activation with rosiglitazone in WT mice reduced LPC expansion in the CDE model, a finding that was consistent with the phenomenon reported by Cheng et al. [30] and Knight et al. [31] that PPARG can inhibit LPC growth and viability. We further explored whether PPARG was involved in BEX1-regulated LPC expansion. Pparg was silenced in LPCs from CDE diet-fed WT and $B e x 1^{-1-}$ mice, reversing the inhibited proliferation and

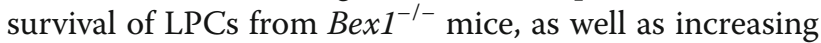
$M y c$ expression and decreasing Cdkn1a mRNA expression. What is more, the PPARG antagonist GW9662 could reverse the decreased Epcam expression and the decreased percentage of EpCAM ${ }^{+}$LPCs in the liver tissues of CDE diet-fed Bex1 $1^{-/-}$mice, and GW9662 could inhibit severe liver injury in CDE diet-fed $B e x 1^{-/-}$mice. Thus, mechanistically, we delineate a previously unrecognized BEX1-regulated pathway in the regulation of LPC activation and expansion through compromising PPARG signalling, promoting LPC proliferation and survival.

Knight et al. [31] demonstrated that PPARG regulated the growth and apoptosis of murine LPCs but did not affect their hepatic differentiation. This finding may explain why BEX1 inhibition has no effect on hepatic differentiation of LPCs in our experiments. PPARG has also been reported to regulate hepatocyte lipogenesis and has demonstrated a prosteatotic role in the liver because mice with hepatocyte deletion of Pparg were protected from high-fat diet-induced steatosis [32, 38]. In our experiment, a population of BEX1 $1^{+}$hepatocytes was observed in $\mathrm{CDE}$ diet-fed mice, and CDE diet-fed $B e x 1^{-1-}$ mice showed more serious macrovesicular steatosis. Thus, it is plausible that BEX1 regulation of PPARG may also function in hepatocytes in this injury model, a phenomenon that requires further investigation.

\section{Conclusions}

In summary, the current study showed that hepatic BEX1 expression was increased during CDE diet-induced liver injury and was elevated to a high level, primarily in LPCs. BEX1 was required for LPC activation and liver regeneration during $\mathrm{CDE}$-induced liver injury by promoting the proliferation and preventing the apoptosis of LPCs. Additionally, BEX1 was required for the colony formation of LPCs but not for their hepatic differentiation. Furthermore, these effects of BEX1 on LPCs were exerted by negatively regulating PPARG signalling. Our study provides insights into the regulation network of BEX1 for LPCs and potentially provides novel targets for liver regeneration and chronic liver disease therapies.

\section{Additional file}

Additional file 1: Figure S1. Genetic ablation of Bex 1 in mice. Genomic DNA was isolated, and genotyping of Bex 1 performed using PCR. Primers as follows: Bex 1-3', TTCATTTCCCCATCTGAAAGGTCCG; Bex 15', TCCCACCTACTCACCCATCCTTCTGG; LTR-5', AAATGGCGTTACTTAAGCT AGCTTGC. Product size for WT mice is $352 \mathrm{bp}$, and for Bex $1^{-1-}$ mice is $223 \mathrm{bp}$ (PDF $47 \mathrm{~kb}$ )

\section{Abbreviations}

ALB: Albumin; ALT: Alanine aminotransferase; Bcl-2: B-cell lymphoma-2; BEX1: Brain-expressed X-linked 1; BrdU: Bromodeoxyuridine; CCK8: Cell Counting Kit-8; CDE: Choline-deficient, ethionine-supplemented; CK19: Cytokeratin-19; DMSO: Dimethyl sulphoxide; EpCAM: Epithelial cell adhesion molecule; FGF: Fibroblast growth factor; G-6-Pase: Glucose-6phosphatase; H\&E: Haematoxylin and eosin; IF: Immunofluorescence; LEPC: Liver epithelial progenitor cell; LPC: Liver progenitor cell; NPC: Nonparenchymal cell; PARP: Poly ADP-ribose polymerase; PAS: Periodic acidSchiff; PBS: Phosphate-buffered saline; PBST: PBS containing 0.1\% Tween-20; PCR: Polymerase chain reaction; PFA: Paraformaldehyde; PI: Propidium iodide; PPARG: Peroxisome proliferator-activated receptor gamma; WT: Wild-type

\section{Acknowledgements}

The authors thank Professor Frank L. Margolis (University of Maryland School of Medicine, Baltimore, MD, USA) for kindly providing the Bex ${ }^{-1-}$ mice and anti-BEX1 antibody.

\section{Funding}

This study was supported by the National Natural Science Foundation of China $(81670540,81502607,81471217)$ and the Ministry of Science and Technology of China (2015CB943303, 2014CB943303, 2011CB966200).

\section{Availability of data and materials}

The datasets supporting the conclusions of this article are included within the article.

\section{Authors' contributions}

YG and WW performed most of the experiments, interpreted the results and wrote the manuscript. YC and XD performed the animal model experiments and helped to interpret the results. HW and BW helped to write and revise the manuscript. MJ performed the acquisition, analysis and interpretation of experiment data, and helped to write and revise the manuscript. $Y Z$ designed the research, helped to write and revise the manuscript, and 
supervised and approved the study. All authors were involved in drafting or revising the manuscript. All authors read and approved the final manuscript.

\section{Ethics approval and consent to participate}

All procedures were conducted with the approval of the ethics committee of Shanghai Jiao Tong University School of Medicine and in accordance with the Animal Welfare \& Ethics Committee of Shanghai Jiao Tong University School of Medicine.

\section{Competing interests}

The authors declare that they have no competing interests.

\section{Publisher's Note}

Springer Nature remains neutral with regard to jurisdictional claims in published maps and institutional affiliations.

\section{Author details}

${ }^{1}$ Pediatric Institute of Soochow University, Institutes for Translational Medicine, Soochow University, Suzhou, Jiangsu, China. ${ }^{2}$ Department of Pediatric Surgery, Xinhua Hospital Affiliated to Shanghai Jiao Tong University School of Medicine, Shanghai, China. ${ }^{3}$ Shanghai Institutes for Biological Sciences, Chinese Academy of Sciences, 320 Yueyang Road, Shanghai 200031, China. ${ }^{4}$ Department of Pharmacy, the Affiliated Suzhou Municipal Hospital, Nanjing Medical University, Suzhou, Jiangsu, China.

\section{Received: 30 December 2017 Revised: 8 May 2018}

\section{Accepted: 15 May 2018 Published online: 15 June 2018}

\section{References}

1. Stanger BZ. Cellular homeostasis and repair in the mammalian liver. Annu Rev Physiol. 2015;77:179-200.

2. Miyajima A, Tanaka M, Itoh T. Stem/progenitor cells in liver development, homeostasis, regeneration, and reprogramming. Cell Stem Cell. 2014;14: 561-74

3. Itoh T. Stem/progenitor cells in liver regeneration. Hepatology. 2016;64:663-8

4. Wang C, Yang W, Yan HX, Luo T, Zhang J, Tang L, Wu FQ, Zhang HL, Yu LX, Zheng LY, Li YQ, Dong W, He YQ, Liu Q, Zou SS, Lin Y, Hu L, Li Z, Wu MC, Wang HY. Hepatitis B virus $X(\mathrm{HBX})$ induces tumorigenicity of hepatic progenitor cells in 3,5-diethoxycarbonyl-1,4-dihydrocollidine-treated $\mathrm{HBX}$ transgenic mice. Hepatology. 2012;55:108-20.

5. Michalopoulos GK. Liver regeneration. J Cell Physiol. 2007;213:286-300.

6. Fausto N. Liver regeneration and repair: hepatocytes, progenitor cells, and stem cells. Hepatology. 2004;39:1477-87.

7. Lowes KN, Brennan BA, Yeoh GC, Olynyk JK. Oval cell numbers in human chronic liver diseases are directly related to disease severity. Am J Pathol. 1999:154:537-41.

8. Weng HL, Feng DC, Radaeva S, Kong XN, Wang L, Liu Y, Li Q, Shen H, Gao YP, Mullenbach R, Munker S, Huang T, Chen JL, Zimmer V, Lammert F, Mertens PR, Cai WM, Dooley S, Gao B. IFN-gamma inhibits liver progenitor cell proliferation in HBV-infected patients and in 3,5-diethoxycarbonyl-1,4dihydrocollidine diet-fed mice. J Hepatol. 2013;59:738-45.

9. Carpino G, Renzi A, Onori P, Gaudio E. Role of hepatic progenitor cells in nonalcoholic fatty liver disease development: cellular cross-talks and molecular networks. Int J Mol Sci. 2013;14:20112-30.

10. Boulter L, Govaere O, Bird TG, Radulescu S, Ramachandran P, Pellicoro A, Ridgway RA, Seo SS, Spee B, Van Rooijen N, Sansom OJ, Iredale JP, Lowell S, Roskams T, Forbes SJ. Macrophage-derived Wnt opposes Notch signaling to specify hepatic progenitor cell fate in chronic liver disease. Nat Med. 2012;18:572-9.

11. Li Z, Chen J, Li L, Ran JH, Li XH, Liu ZH, Liu GJ, Gao YC, Zhang XL, Sun HD. Human hepatocyte growth factor (hHGF)-modified hepatic oval cells improve liver transplant survival. PLoS One. 2012;7:e44805.

12. Wu CX, Zou Q, Zhu ZY, Gao YT, Wang YJ. Intrahepatic transplantation of hepatic oval cells for fulminant hepatic failure in rats World. J Gastroenterol. 2009;15:1506-11.

13. Takase HM, Itoh T, Ino S, Wang T, Koji T, Akira S, Takikawa Y, Miyajima A. FGF7 is a functional niche signal required for stimulation of adult liver progenitor cells that support liver regeneration. Genes Dev. 2013;27:169-81.

14. Kallis YN, Robson AJ, Fallowfield JA, Thomas HC, Alison MR, Wright NA, Goldin RD, Iredale JP, Forbes SJ. Remodelling of extracellular matrix is a requirement for the hepatic progenitor cell response. Gut. 2011;60:525-33.
15. Zhang W, Chen XP, Zhang WG, Zhang F, Xiang S, Dong HH, Zhang L. Hepatic non-parenchymal cells and extracellular matrix participate in oval cell-mediated liver regeneration. World J Gastroenterol. 2009;15:552-60.

16. Apte U, Thompson MD, Cui S, Liu B, Cieply B, Monga SP. Wnt/beta-catenin signaling mediates oval cell response in rodents. Hepatology. 2008;47:288-95.

17. Faria TN, LaRosa GJ, Wilen E, Liao J, Gudas LJ. Characterization of genes which exhibit reduced expression during the retinoic acid-induced differentiation of F9 teratocarcinoma cells: involvement of cyclin D3 in RAmediated growth arrest. Mol Cell Endocrinol. 1998;143:155-66.

18. Vilar M, Murillo-Carretero M, Mira H, Magnusson K, Besset V, Ibanez CF. Bex1, a novel interactor of the $\mathrm{p} 75$ neurotrophin receptor, links neurotrophin signaling to the cell cycle. EMBO J. 2006;25:1219-30.

19. Carter BDA. Bex-cycle built for two. EMBO Rep. 2006;7:382-4.

20. Khazaei MR, Halfter H, Karimzadeh F, Koo JH, Margolis FL, Young P. Bex1 is involved in the regeneration of axons after injury. J Neurochem. 2010; 115:910-20

21. Koo JH, Smiley MA, Lovering RM, Margolis FL. Bex1 knock out mice show altered skeletal muscle regeneration. Biochem Biophys Res Commun. 2007; 363:405-10.

22. Braeuning A, Jaworski M, Schwarz M, Kohle C. Rex3 (reduced in expression 3) as a new tumor marker in mouse hepatocarcinogenesis. Toxicology. 2006;227:127-35.

23. Akhurst B, Croager EJ, Farley-Roche CA, Ong JK, Dumble ML, Knight B, Yeoh GC. A modified choline-deficient, ethionine-supplemented diet protocol effectively induces oval cells in mouse liver. Hepatology. 2001;34:519-22.

24. Cheng Y, Wang X, Wang B, Zhou H, Dang S, Shi Y, Hao L, Luo Q, Jin M, Zhou Q, Zhang Y. Aging-associated oxidative stress inhibits liver progenitor cell activation in mice. Aging (Albany NY). 2017;9:1359-74.

25. Zhang Y, Cai W, Huang Q, Gu Y, Shi Y, Huang J, Zhao F, Liu Q, Wei X, Jin M, Wu C, Xie Q, Zhang Y, Wan B, Zhang Y. Mesenchymal stem cells alleviate bacteria-induced liver injury in mice by inducing regulatory dendritic cells. Hepatology. 2014;59:671-82.

26. Li WL, Su J, Yao YC, Tao XR, Yan YB, Yu HY, Wang XM, Li JX, Yang YJ, Lau JT, $\mathrm{Hu}$ YP. Isolation and characterization of bipotent liver progenitor cells from adult mouse. Stem Cells. 2006;24:322-32.

27. Cheng Y, Wang B, Zhou H, Dang S, Jin M, Shi Y, Hao L, Yang Z, Zhang Y. Autophagy is required for the maintenance of liver progenitor cell functionality. Cell Physiol Biochem. 2015;36:1163-74.

28. Okabe M, Tsukahara Y, Tanaka M, Suzuki K, Saito S, Kamiya Y, Tsujimura T, Nakamura K, Miyajima A. Potential hepatic stem cells reside in EpCAM+ cells of normal and injured mouse liver. Development. 2009;136:1951-60.

29. Weng T, Koh CG. POPX2 phosphatase regulates apoptosis through the TAK1-IKK-NF-kappaB pathway. Cell Death Dis. 2017;8:e3051.

30. Cheng J, Nakamura H, Imanishi H, Liu W, Morisaki T, Sugiyama T, Hada T. Peroxisome proliferator-activated receptor gamma ligands, 15-deoxydelta12,14-prostaglandin J2, and ciglitazone, induce growth inhibition and cell cycle arrest in hepatic oval cells. Biochem Biophys Res Commun. 2004; 322:458-64.

31. Knight B, Yeap BB, Yeoh GC, Olynyk JK. Inhibition of adult liver progenitor (oval) cell growth and viability by an agonist of the peroxisome proliferator activated receptor (PPAR) family member gamma, but not alpha or delta. Carcinogenesis. 2005;26:1782-92.

32. Elias-Miro M, Jimenez-Castro MB, Mendes-Braz M, Casillas-Ramirez A, Peralta $C$. The current knowledge of the role of PPAR in hepatic ischemiareperfusion injury. PPAR Res. 2012;2012:802384.

33. Lu WY, Bird TG, Boulter L, Tsuchiya A, Cole AM, Hay T, Guest RV, Wojtacha D, Man TY, Mackinnon A, Ridgway RA, Kendall T, Williams MJ, Jamieson T, Raven A, Hay DC, Iredale JP, Clarke AR, Sansom OJ, Forbes SJ. Hepatic progenitor cells of biliary origin with liver repopulation capacity. Nat Cell Biol. 2015;17:971-83.

34. Brown AL, Kay GF. Bex1, a gene with increased expression in parthenogenetic embryos, is a member of a novel gene family on the mouse X chromosome. Hum Mol Genet. 1999;8:611-9.

35. Yang QS, Xia F, Gu SH, Yuan HL, Chen JZ, Yang QS, Ying K, Xie Y, Mao YM. Cloning and expression pattern of a spermatogenesis-related gene, BEX1, mapped to chromosome Xq22. Biochem Genet. 2002:40:1-12.

36. Sagawa H, Naiki-Ito A, Kato H, Naiki T, Yamashita Y, Suzuki S, Sato S, Shiomi K, Kato A, Kuno T, Matsuo Y, Kimura M, Takeyama H, Takahashi S. Connexin 32 and luteolin play protective roles in non-alcoholic steatohepatitis development and its related hepatocarcinogenesis in rats. Carcinogenesis. 2015;36:1539-49. 
37. Berger J, Moller DE. The mechanisms of action of PPARs. Annu Rev Med. 2002:53:409-35.

38. Moran-Salvador E, Lopez-Parra M, Garcia-Alonso V, Titos E, MartinezClemente M, Gonzalez-Periz A, Lopez-Vicario C, Barak Y, Arroyo V, Claria J.

Role for PPARgamma in obesity-induced hepatic steatosis as determined by hepatocyte- and macrophage-specific conditional knockouts. FASEB J. 2011; 25:2538-50.

Ready to submit your research? Choose BMC and benefit from:

- fast, convenient online submission

- thorough peer review by experienced researchers in your field

- rapid publication on acceptance

- support for research data, including large and complex data types

- gold Open Access which fosters wider collaboration and increased citations

- maximum visibility for your research: over $100 \mathrm{M}$ website views per year 